\title{
O PERFIL IDEAL DE FRANQUEADO, AS MOTIVAÇÕES PARA A INSERÇÃO NO SISTEMA DE FRANQUIAS E A PERCEPÇÃO DO RELACIONAMENTO COM O FRANQUEADOR: UM ESTUDO DE CASO EM UMA REDE DE DROGARIAS
}

Luiz Fernando Gonçalves Da Silva Araújo Jefferson Alves Da Silva Oliveira ${ }^{1}$ Euslany Gomes De Oliveira Alves ${ }^{1}$ Tálitha De Souza Silva ${ }^{1}$

${ }^{1}$ Pontifícia Universidade Católica de Goiás 


\section{O PERFIL IDEAL DE FRANQUEADO, AS MOTIVAÇÕES PARA A INSERÇÃO NO SISTEMA DE FRANQUIAS E A PERCEPÇÃO DO RELACIONAMENTO COM O FRANQUEADOR: UM ESTUDO DE CASO EM UMA REDE DE DROGARIAS}

Resumo: O presente estudo analisou o perfil ideal de franqueado para a rede de drogarias DrogaShop, as motivações dos franqueados para a inserção no sistema de franquias e a percepção do relacionamento com o franqueador. A pesquisa é caracterizada como descritiva, tipo qualitativa com entrevista estruturada. Verificou-se que não existe um perfil ideal de franqueado para a DrogaShop, mas é observado a capacidade de planejamento, expectativas em relação ao tempo de retorno do investimento e a disposição do futuro franqueado para dedicarse ao negócio. As motivações dos franqueados, direcionam-se para formas mais seguras de investimento, vantagem competitiva, economia de escala, força da marca e suporte técnico. A relação com o franqueador é positiva, com atendimento frente as demandas apresentadas e suporte técnico. $\mathrm{O}$ estudo continua aberto para novas abordagens, incluindo a ampliação da pesquisa na rede de drogarias DrogaShop, com a perspectiva de mapear estrategicamente o perfil dos franqueados.

Palavras-Chave: Franquia. Franqueador. Franqueado. DrogaShop.

\section{Introdução}

O cenário econômico brasileiro apresentou nos últimos anos, consideradas transformações, bem como, oscilações, gerando recessão e crescimento em momentos distintos, mas em especial, o setor de franquias, tem sido palco de grandes discussões, atualmente, é uma questão quase que obrigatória quando se fala em expansão e desenvolvimento de mercados (ANJOS, 2015). O setor apontou significativo crescimento, evidenciando sua força e dinamismo frente as demandas do mercado, com o surgimento de novas redes nacionais e internacionais, incluindo a consolidação de marcas tradicionais.

O sistema de franquias tem atraído atenção de muitos investidores e empreendedores, recebendo altos investimentos e ganhando força por meio das mídias e da sociedade em geral. As franquias caracterizam-se como um sistema no qual um franqueador concede o direito de uso de uma marca e/ou de procedimentos específicos para determinados franqueados, com isso, realiza-se um negócio padronizado, restituindo o franqueador pelo direito de uso da marca, know-how e seus respectivos processos, sejam eles, operacionais ou de gestão (COMBS; KETCHEN, 2003; PARENTE, 2000).

O Brasil sempre foi um campo fértil para inovações e isso também aconteceu com o franchising, ou seja, o sistema foi absorvido rapidamente e o país é hoje um dos expoentes mundiais, não apenas em quantidade de franquias, mas no próprio aprimoramento do sistema (MAURO, 2007). O mercado de franquias é relativamente novo no Brasil, mas tem representado uma parcela significativa no ganho econômico do país com potencial gerador de empregos e de novas formas de estabelecer negócios. 
O sistema de franchising encontra-se em um cenário que exige bastante articulação entre franqueador e franqueado, além da necessidade de munirem-se de meios que possibilite o alcance dos objetivos. Diante do exposto, a problemática do estudo direciona-se ao franqueador e aos franqueados da rede de Drogarias DrogaShop. Ao franqueador, levanta a seguinte questão: "Qual o perfil desejado e quais as habilidades fundamentais que o franqueado deve ter ou adquirir?" Aos franqueados, questiona-se: "Quais foram suas maiores motivações para a aquisição de uma franquia e Como é seu relacionamento com o franqueador?"

A pertinência do estudo justifica-se ao propor examinar os fatores e situações decorrentes da relação entre franqueador e franqueados, temática de extrema importância para aqueles que buscam investir em uma base de negócio já consolidada e com menor risco de investimentos. Acrescenta-se ainda a importância ao público empreendedor e também investidor, possibilitando o acesso a um estudo de caso aplicado, que se soma a outros, aumentando o portfólio de casos práticos direcionados ao sistema de franchising. Tais contribuições, visam a elevação dos índices de êxito das franquias, seja por meio do desenvolvimento e/ou reformulação das estratégias de distribuição, comercialização, operação, gestão, dentre outros. Quanto mais estruturado estiver o sistema de franchising, maior será o desenvolvimento, a maximização de resultados e consequentemente a expansão desse mercado.

O estudo está estruturado em quatro sessões, a primeira apresenta a fundamentação teórica, com breve abordagem sobre o sistema de franquias, bem como a relação entre franqueador e franqueado. A segunda sessão, descreve a metodologia, a terceira, apresenta a análise e discussão dos resultados. Por último, a quarta sessão, elucida as considerações finais.

\section{Referencial Teórico \\ $2.1 \mathrm{O}$ sistema de franquias}

A definição formal para o termo "franquia", descreve-a como um acordo contratual entre duas partes (franqueador e franqueado), que entre si celebram por meio de instrumento contratual as bases do negócio, em que ambos terão contrapartidas a serem realizadas (HITT; IRELAND; HOSKISSON, 2001). Por outra perspectiva, ressalta que o sistema de franquias atribui responsabilidades ao franqueador e ao franqueado, o primeiro com o papel de desenvolver sistemas comerciais relacionados à marca, inovação, gestão e ao crescimento do negócio, já o franqueado deve seguir as diretrizes definidas pelo modelo de franquia adquirido, implementar melhorias em seu estabelecimento e zelar pelo nome do empreendimento, tendo em vista que a identidade global da franquia é que está em jogo, assim, qualquer deslize de uma das partes (franqueador e franqueado), tende a prejudicar o negócio (SOUZA; LOURENZANI, 2010).

Franquia tem entre suas definições, o descrito no Art. $2^{\circ}$ da Lei $\mathrm{n}^{\circ} 8.955$, de 15 de dezembro de 1994, que específica o seguinte:

Franquia empresarial é o sistema pelo qual um franqueador cede ao franqueado o direito de uso da marca ou patente, associado ao direito de distribuição exclusiva ou semi-exclusiva de produtos ou serviços e, eventualmente, também ao direito de uso de tecnologia de implantação e administração de negócio ou sistema operacional desenvolvidos ou detidos pelo franqueador, mediante remuneração direta ou indireta, sem que, no entanto, fiquem caracterizado vínculo empregatício (BRASIL, 1994). 
O sistema de franquias é visto por muitos como sinônimo de sucesso e existe uma grande expectativa, mesmo levando em comparação todos os riscos envolvidos. Sob essa perspectiva, Mauro (2006), descreve que esse sistema faz parte da tendência mundial para uma maior integração dos membros pertencentes ao canal de distribuição, do fabricante até o consumidor final. Neste contexto, Isaac, Melo e Borini (2018, p. 48), destacam que se tem "visualizado uma crescente busca na compreensão do modelo de franchising e da competitividade das redes de franquias em atuação nos mercados emergentes, em especial daquelas estrangeiras oriundas de países desenvolvidos".

Para Correa, Hoeltegebaum e Machado (2006), o sistema de franchising, compreende uma possibilidade a mais para investir e empreender com maior grau de segurança, servindo como alternativa ao empreendedor que deseja estabelecer-se com marcas e know-how consolidados pelos franqueadores, fator que contribui para reduzir as incertezas presentes ao abrir um negócio. Corroborando, Luiz et al., (2006), descrevem que um dos motivos que contribuem para aderência do mercado ao sistema de franquias, volta-se para as vantagens que o sistema oferece, essas, são superiores aos negócios independentes, principalmente por fornecerem ao empreendedor um modelo de gestão com foco na parceria, maior troca de informações, além da inserção de práticas inovadoras nos mercados e estratégias de diferenciação.

Azevedo e Silva (2003), acrescentam outros benefícios identificados nas franquias, entre esses, os ganhos de escala, decorrentes do acesso tecnológico possibilitado pelo franqueador, maior facilidade na obtenção de financiamentos para expansão do empreendimento e/ou capital de giro, menor dispêndio de recursos para o monitoramento e controle das unidades, quando comparado às lojas próprias, uma vez que o processo administrativo está bem desenhado e sob constante adequação.

Neste contexto, (MELO; BORINI; CUNHA, 2014), relatam que no sistema de franchising, o franqueador assume a responsabilidade pelo desenvolvimento da marca, produtos, compartilhamento do know-how de operação e capacitação dos franqueados. Tais fatores, contribuem para a atratividade do negócio, seja pela aquisição de conhecimentos, como pelas práticas comerciais disponibilizadas ao franqueado. Desta forma, o suporte por parte do franqueador faz com que o sistema de franquias apresente menores riscos de insucesso do que os negócios independentes. Por sua vez, o franqueado, em troca do suporte recebido, recompensa o franqueador por meio de taxas de instalação da franquia, publicidade e royalties.

De acordo com (MAURO, 2007), quando analisamos o sistema de franchising, não se faz referência a um modismo e, sim, a uma evolução dos canais de distribuição, de uma situação irreversível aprovada pelo consumidor final, considerando seu nível de exigência, acesso a fontes diversas de informações e crescente poder de negociação. Essa é tida como a evolução gerada pela competição do capitalismo moderno, ou seja, enquanto os canais convencionais representam a ineficiência e os conflitos crescentes, o sistema de franchising representa a integração, perpetuidade e socialização dos resultados da rede.

No Brasil o sistema de franquias no Brasil, teve início na década de 50, de forma incipiente, com a chegada das escolas de idiomas, como a Yázigi em São Paulo. O crescimento desse setor teve ascensão a partir da criação da Associação Brasileira de Franchising (ABF), em 1987, somado à fatores como o aumento do número de shoppings centers, além do crescimento e desenvolvimento dos centros urbanos (MASCARENHA; HYGINO; SILVA, 2015). Para Rodrigues (2010), o sistema de franquias no país, possibilita que inúmeras empresas possam nascer com melhor estrutura organizacional, e consequentemente, melhor aplicação dos 
recursos materiais e financeiros, bem como, o acesso a novas tecnologias, tais fatores têm possibilitado mais crescimento e solidez neste mercado altamente dinâmico e competitivo.

Entre as diversas formas de empreender no Brasil, as franquias foram rapidamente absorvidas e são cultuadas como um meio seguro e promissor para iniciar um negócio. Sob essa perspectiva, Mauro (2007), expõe que o Brasil sempre foi um campo fértil para inovações, não sendo diferente no processo de entrada e expansão do sistema de franchising.

Segundo o Sebrae (2018), no Brasil existem vários tipos de franquias em atuação, dentre as principais, a franquia unitária, caracterizada como por ceder o direito de abertura de uma unidade, com exclusividade de atuação em local determinado pelo franqueador; a franquia master, modelo utilizado nos planos de internacionalização de franquias e em países de grandes dimensões geográficas; a franquia de desenvolvimento de área, nesta, cede-se o direito para exploração de uma determinada região, onde o franqueado abrirá mais de uma unidade em um determinado período de tempo; e por último, a micro franquia, caracterizada por exigir baixo investimento, custo operacional mínimo e operação simplificada, além de atividades que podem ser realizadas pelo franqueado e, muitas vezes, sem exigência de um ponto comercial.

Ao analisar o cenário econômico correspondente ao período de 2014 a 2018, mesmo com as adversidades e desafios econômicos, constata-se um crescimento, ainda que tímido. Os números de crescimento no faturamento de 2017 para 2018, apresentam aumento de 7,1\%. Já as quantidades de unidades de franquias cresceram 5,2\% no mesmo período, gerando a criação de novas vagas de emprego, equivalente a $8,8 \%$ em relação ao ano anterior (ABF, 2018). Segundo o Sebrae (2018), apesar do crescimento no setor de franquia, o Brasil ainda registra o maior índice de mortalidade de empresas em seu início, ou seja, cerca de $50 \%$ das empresas morrem no primeiro ano, chegando a $80 \%$ quando se analisa os cinco primeiros anos.

A sessão a seguir, elucida de forma breve, algumas características da relação entre franqueador e franqueado, bem como as vantagens e desvantagens compreendidas pelo sistema de franchising.

\subsection{Relação entre Franqueador e Franqueado}

Um empreendedor quando opta por adquirir uma franquia está em busca de um negócio seguro e com bons rendimentos, diante dos diversos aspectos que os franqueadores e franqueados têm que lidar no mercado. A relação entre eles deve ser a mais amigável e sincera possível para que possam gerir todos os processos e fazer o negócio gerar resultados positivos.

Para Mauro (2006), a relação entre franqueado e franqueador deve ser considerada um fator de extrema relevância, devido sua intensidade, pois ambos estão interconectados. Não existe franquia em que não haja recíproca relação de confiança, de modo que o franqueador contribui com sua experiência e auxílio operacional e o franqueado com sua ambição de possuir o negócio, realiza a gestão da franquia, bem como, as contrapartidas acordadas. Como resultado dessa simbiose almeja-se a excelência no atendimento ao consumidor final, com valor agregado ao produto/serviço.

Para, Lima Jr. Luna e Sousa (2012), a relação entre franqueado e franqueador é crucial para o efetivo sucesso do negócio, devendo considerar alguns princípios, dentre esses: a) satisfação com a decisão de adotar o sistema de franquia; b) satisfação do relacionamento com os franqueados; c) interesse em continuar expandindo por meio de unidades franqueadas; d) satisfação com a rentabilidade; e) confiança nos franqueados em relação os compromissos 
previstos; f) visão de franqueados como parceiros e g) as ações dos franqueados afetam o resultado do negócio.

Para Degobbi (2013), os relacionamentos formais e informais entre o franqueador e franqueado são determinantes nos processos de transações realizadas, a fim de reduzir os pontos de entrave, e desta forma, obter maior racionalidade nos procedimentos. Para tanto, é essencial uma da boa negociação; elaboração e execução dos contratos de forma clara e precisa; processo analítico prévio e consistente; administração dos agentes envolvidos e busca por soluções eficientes, mantendo sempre o foco no negócio.

Com relação as vantagens e desvantagens no relacionamento entre franqueador e franqueado, Mascarenhas, Hygino e Silva (2015), destacam que o franqueador se beneficia a partir do momento da abertura de uma franquia, maximizando diretamente e indiretamente as possibilidades de crescimento do negócio, preenchendo de forma rápida as lacunas encontradas no mercado, além da contrapartida financeira proveniente da cessão dos direitos do uso da marca, processos e know-how.

Ao analisar as vantagens de uma franquia para o franqueado, Mauro (2007), destaca as perspectivas de sucesso de um negócio já experimentado pelo mercado, em geral, com marca consolidada, processos bem estruturados, planejamento e pesquisas, orientações e aperfeiçoamentos sob a responsabilidade do franqueador, conhecimento de mercado, além do apoio de especialistas para suporte na melhoria dos pontos fracos e maximização dos pontos fortes. $\mathrm{O}$ autor destaca ainda, a economia em escala, uma vez que as compras são adquiridas em grandes volumes, somado a facilidade de acesso ao crédito.

O quadro 1 descreve o contexto exposto acima, com as principais vantagens do sistema de franquias, tanto para o franqueador quanto para o franqueado.

\section{Quadro 1 - Vantagens do sistema de franquias}

\begin{tabular}{|c|c|}
\hline Franqueador & Franqueado \\
\hline Cobertura mais eficiente de mercado & Know-how adquirido \\
\hline $\begin{array}{l}\text { Crescimento com capital de terceiros } \\
\text { (franqueado) }\end{array}$ & Apoio de especialistas \\
\hline Desenvolvimento de uma rede & Economia de escala \\
\hline Fortalecimento e expansão da marca & Facilidade de acesso à crédito \\
\hline Imagem corporativa & Maior chance de sucesso \\
\hline $\begin{array}{l}\text { Maior rapidez na expansão de mercado } \\
\text { (cobertura geográfica) }\end{array}$ & Maior vantagem competitiva \\
\hline Maior vantagem competitiva & $\begin{array}{l}\text { Pertencimento a um grupo ou corporação } \\
\text { Retorno sobre investimento (ROI) mais } \\
\text { rápido }\end{array}$ \\
\hline
\end{tabular}

Fonte: Elaborado pelos autores, adaptado de Kich (2013) e Rodrigues (2010).

Por outro lado, tanto o franqueador como o franqueado estão à mercê de desvantagens, segundo, Gigliotti (2010) entre as possíveis desvantagens para o franqueador está o risco quanto à possibilidade de perder o controle da operação, uma vez que o quadro de pessoal que atua na franquia não está sob sua gestão. A falta de gestão/controle pode levar a vários problemas, principalmente pela negligência do franqueado com relação a devida e correta inserção das informações e consequentemente a manipulação dos resultados expressos nos relatórios para apuramento da contrapartida financeira. Outro ponto sensível, relaciona-se com a dificuldade 
em manter um padrão de imagem, de qualidade dos produtos/serviços, bem como, a padronização das promoções de vendas e a fiel execução das receitas e processos, tidos como cruciais para a entrega da qualidade requerida pelo mercado consumidor.

Com relação as desvantagens que atingem o franqueado, Mascarenhas, Hygino e Silva (2015) e Silva (2014), destacam a autonomia parcial no negócio, pois grande parte das questões de gestão do produto/serviço estão previamente estabelecidas e devem seguir controles definidos pelo franqueador; acrescenta ainda os riscos associados ao desempenho do franqueador, combinados com o pagamento contínuo de taxas e royalties sobre o volume das vendas.

O quadro 2 corrobora com o contexto exposto, relacionando as principais desvantagens do sistema de franquias.

Quadro 2 - Desvantagens do sistema de franquias

\begin{tabular}{l|l}
\hline \multicolumn{1}{c}{ Franqueador } & \multicolumn{1}{c}{ Franqueado } \\
\hline Maior custo de supervisão & Autonomia parcial \\
Perda de padronização & Controles rígidos \\
Perda parcial do controle & Localização forçada \\
& $\begin{array}{l}\text { Risco associado ao desempenho do } \\
\text { franqueador } \\
\text { Perdas de sigilo }\end{array}$ \\
Procedimentos para seleção de pessoal & Risco de desistência \\
\hline
\end{tabular}

Fonte: Elaborado pelos autores, adaptado de Kich (2013) e Rodrigues (2010).

Considerando o exposto, o sistema de franquias como qualquer outro mercado apresenta fatores positivos e negativos, Mauro (2006), descreve esse sistema como uma rede inteligente e expressamente integrada, que exige fidelidade do franqueador e do franqueado para que juntos possam identificar estratégicas e colocá-las em práticas, a fim de obter o melhor resultado para o negócio.

\section{Metodologia}

O presente estudo, desenvolve-se inicialmente com uma breve revisão bibliográfica sobre o sistema de franquias "franchising", bem como, a relação entre franqueador e franqueado, evidenciando suas vantagens e desvantagens. Com relação aos objetivos, a pesquisa caracteriza-se como descritiva, pois reside na investigação empírica cuja a principal finalidade é o delineamento ou análise das características de fatos ou fenômenos. Com relação aos procedimentos técnicos, enquadra-se como estudo de caso (LAKATOS, 2003).

A abordagem utilizada no estudo é a qualitativa, ou seja, consiste no pensamento que há uma relação indissociável entre o sujeito e o objeto pesquisado, não sendo possível ser traduzido por números, visto que as particularidades do ser devem ser respeitadas. $\mathrm{O}$ instrumento utilizado para a coleta de dados, foi a entrevista, cuja finalidade é obter informações sobre determinado assunto ou problema. Optou-se pela entrevista padronizada/estruturada, com roteiro previamente elaborado (FARIAS FILHO; ARRUDA FILHO, 2013; SILVA; MENEZES, 2005).

O estudo de caso foi realizado na rede de drogarias DrogaShop, empresa goiana, atuante no segmento de medicamentos e produtos de higiene pessoal, que desde o ano 2013 tem seu processo de expansão direcionado ao sistema de Franchising. A empresa tem como Missão,

DOI: $10.14211 / x i-e g e p e-118023$ 
"ser referência no mercado de drogarias, garantindo conforto, comodidade, praticidade e economia a nossos clientes, e resultados positivos aos nossos franqueados". Para a Visão do negócio, almeja "tornar-se uma marca de expressão nacional, crescendo de forma sustentável e rentável". Os valores institucionais estão pautados na "Atitude, Foco, Ousadia e Amor".

As entrevistas ocorreram entre o período de 07 de maio a 31 de julho de 2019, respeitando os critérios de individualidade e impessoalidade. Em um primeiro momento foi entrevistado o Diretor Executivo da DrogaShop, Sr. Ademar Junior (franqueador), posteriormente, entrevistou o Sr. Paulo César e o Sr. Thiago Cardoso (franqueados), o primeiro com uma loja na região do setor Cidade Livre e o segundo no setor Veiga Jardim, ambas situadas em Aparecida de Goiânia, Goiás.

Após a coleta de dados, realizou-se a transcrição na integra das entrevistas (franqueador e franqueado), posteriormente, foram relacionadas as variáveis, a partir da interpretação e interação das falas dos entrevistados, relacionando-as com o referencial teórico.

\section{Análise e Discussão dos Resultados}

A partir das informações obtidas por meio das entrevistas realizadas com o franqueador e os franqueados, a presente sessão discorre acerca das respostas obtidas, para posteriormente, analisá-las com subsídio junto ao referencial teórico.

O quadro 3 e 4 elucidam as respostas do franqueador e dos franqueados, com base na problemática levantada, a fim compreender as expectativas do franqueador em relação ao franqueado, considerando o portfólio de características que julga ser essencial para o bom desempenho da franquia. Por outro lado, elenca-se as motivações dos franqueados para sua adesão ao sistema de franquias, bem como a percepção do relacionamento com franqueador.

Quadro 3 - Perspectivas do franqueador e fraqueado: perfil/características desejadas pelo franqueador e as motivações do franqueado para adesão ao sistema de franquias

\begin{tabular}{|c|c|}
\hline Franqueador & Franqueado \\
\hline $\begin{array}{l}\text { Pergunta: Qual o perfil desejado e quais } \\
\text { as habilidades fundamentais que o } \\
\text { franqueado deve ter ou adquirir? }\end{array}$ & $\begin{array}{l}\text { Pergunta: Quais foram suas maiores } \\
\text { motivações para a aquisição de uma } \\
\text { franquia? }\end{array}$ \\
\hline $\begin{array}{l}\text { Resposta: Ademar Junior } \\
\text { Não existe um perfil ideal para atuar no } \\
\text { sistema de franquias de drogarias, [...] o } \\
\text { que existe e é necessário avaliar, são as } \\
\text { características e as habilidades, bem como } \\
\text { seu planejamento e expectativa a curto e } \\
\text { longo prazo. É interessante verificar se o } \\
\text { futuro franqueado tem características } \\
\text { empreendedoras, porque principalmente } \\
\text { no início o franqueado tem que "rala" e } \\
\text { não apenas investir o dinheiro e pronto } \\
\text { [...]. Já em relação as habilidades, é } \\
\text { importante saber se relacionar com } \\
\text { pessoas, tanto com os funcionários }\end{array}$ & $\begin{array}{l}\text { Resposta: Paulo Cesar } \\
\text { [...] a franquia eu iniciei em } 2016 \text {, e antes } \\
\text { da franquia eu trabalhava independente } \\
\text { [...]. No mercado era difícil atuar meio que } \\
\text { só, então isso dificultou muito a empresa } \\
\text { a crescer, porque não tinha muito credito } \\
\text { do consumidor, não tinha muito como } \\
\text { precificar [...] não tinha como adquirir } \\
\text { mercadoria com um preço melhor. Então } \\
\text { esse foi o motivo que me levou a comprar } \\
\text { a franquia [...]. Outro ponto é a questão da } \\
\text { marca, ela se fortaleceu bastante no Cento } \\
\text { Oeste, [...] então a marca ela traz o cliente } \\
\text { para dentro da loja e traz uma confiança }\end{array}$ \\
\hline
\end{tabular}


quantos com os clientes, tem que querer e é fundamental atuar no operacional, ou seja, estar sempre na farmácia para atendimento e resolução de possíveis problemas.

Fonte: Elaborado pelos autores.

maior, uma estabilidade até maior aos olhos do cliente, este é outro motivo que me levou a ter uma franquia.

\section{Resposta: Thiago Cardoso}

[...] quando eu decidi a comprar a franquia, no caso a DrogaShop foi um negócio que um outro franqueado ia abrir lá, [...], eu comprei toda estrutura que ele já tinha montado e abri essa drogaria. [...] eu fui estudar mais a fundo como era esse mercado de farmácia, [...] a franquia me ajudou muito na questão de compras, negociação, de suporte né, suporte tanto em venda, financeiro, o suporte em gestão, então analisei tudo isso daí, isso foi alguns dos motivos que escolhi a franquia, por enquanto está me ajudando nesse requisito.

Ao analisar o depoimento do franqueador com relação ao perfil desejado e quais as habilidades fundamentais que o franqueado deve ter ou adquirir, depare-se com a seguinte afirmação: [...] não existe um perfil ideal para atuar no sistema de franquias de drogarias, o que existe e é necessário avaliar, são as características e as habilidades, bem como seu planejamento e expectativa a curto e longo prazo. Esse posicionamento vai ao encontro de Mauro (2007), ao descrever que o franqueador contribui com sua experiência e auxílio operacional e o franqueado com seu planejamento e ambição de possuir o negócio.

Ainda com referência às habilidades esperadas para o franqueado, destaca-se a importância em relação as características empreendedoras, conforme destacado pelo franqueador [...] no início o franqueado tem que "rala" e não apenas investir o dinheiro e pronto [...]. O contexto exposto, alinha-se à afirmação de Toledo (2005) apud Mascarenhas, Hygino e Silva (2015) e Rodrigues (2010), ao enfatizar que o perfil do público que busca investir no sistema de franquias, tem se alterado, no passado, os franqueados, tinham uma percepção muito voltada para o investimento, ou seja, o capital aplicado na franquia. Com o passar do tempo, e consequentemente com a evolução da percepção sobre o sistema de franquias, e sua própria evolução, passou a atrair investidores com perfil mais empreender, disposto a participar ativamente do negócio, voltado para desafios e inovação.

Acerca das habilidades consideradas necessárias pelo franqueador, destaca-se as habilidades de relacionamento, dentre essas, com funcionários e clientes. Segundo, Mauro (2007), o relacionamento sadio entre as partes, contribui para a excelência no atendimento ao consumidor final, gerando vantagem competitiva e diferenciação no mercado. Outro ponto importante, é a capacidade para atuar na área operacional, ou seja, estar sempre na farmácia para atendimento de balcão e resolução de problemas do dia a dia do negócio. 
Por outro lado, os franqueados ao serem questionados quanto as motivações para aquisição uma franquia, obteve-se os seguintes argumentos: [...] no mercado era difícil atuar meio que só [...]; não tinha muito credito do consumidor, não tinha muito como precificar [...]; não tinha como adquirir mercadoria com um preço melhor. [...]; outro ponto é a questão da marca, ela se fortaleceu bastante no Cento Oeste [...]; a franquia me ajudou muito na questão de compras, negociação, suporte tanto em venda, financeiro e o suporte em gestão [...].

Ao contextualizar tais argumentações sobre as motivações dos franqueados, verifica-se que o uso da marca como um dos pontos fundamentais para adesão ao sistema de franquias, essa carrega consigo um ideal de negócio já testado e aprovado. Corroborando, Degobbi (2013), destaca para a importância dos custos, principalmente pelas formas de obter sua redução, seja, por meio de uma boa negociação; pela elaboração e execução dos contratos; pelo processo analítico prévio e consistente e gestão administrativa.

Com relação as vantagens que motivam os franqueados a investirem no sistema de franquias, verifica-se uma forte relação com os fatores descritos por Kich (2013) e Rodrigues (2010), sendo: economia de escala, facilidade de acesso à crédito, maior chance de sucesso e maior vantagem competitiva.

O quadro 4 apresenta a percepção do franqueado referente ao relacionamento com o franqueador.

Quadro 4 - Percepção do relacionamento do franqueado com o franqueador

\begin{tabular}{l|l}
\hline \multicolumn{1}{c}{ Franqueado - Paulo Cesar } & \multicolumn{1}{c}{ Franqueado - Thiago Cardoso } \\
\hline $\begin{array}{l}\text { Pergunta: Como é seu relacionamento } \\
\text { com o franqueador? }\end{array}$ & $\begin{array}{l}\text { Pergunta: Como é seu relacionamento } \\
\text { com o franqueador? }\end{array}$ \\
\hline Resposta: & $\begin{array}{l}\text { Resposta: } \\
\text { O relacionamento com o franqueador é enho um relacionamento bem próximo }\end{array}$ \\
$\begin{array}{l}\text { ótimo! [...], sempre que a gente solicita } \\
\text { com eles né, tudo que eu preciso é só ligar } \\
\text { algo eles atendem e estão sempre trazendo } \\
\text { algo para a gente também, sempre }\end{array}$ & $\begin{array}{l}\text { lá que eles me atendem, e sempre que eles } \\
\text { podem também, uma vez por mês manda }\end{array}$ \\
trazendo alguma novidade de mercado, & um supervisor para vir na loja né, e \\
como divulgar o produto, como divulgar a & verificar como está o andamento, então \\
loja, então assim, o tempo todo eles estão & assim e tudo monitorado por eles lá, [...] \\
trabalhando para nos ajudar nesse sentido. & isso ajuda na questão administrativo [...]. \\
\hline Fonte: Elaborado pelos autores.
\end{tabular}

Considerando o quadro acima, constata-se que ambos os franqueados, tem um relacionamento positivo com o franqueador, conforme relatos obtidos [...], sempre que a gente solicita algo eles atendem; [...] sempre trazendo alguma novidade de mercado, como divulgar o produto, como divulgar a loja; [...] é um relacionamento bem próximo com eles; [...] uma vez por mês manda um supervisor para vir na loja e verificar como está o andamento, então assim e tudo monitorado por eles [...]. Os relatos obtidos, encontram subsídio em Mauro (2007), ao descrever a relação entre franqueado e franqueador como um fator relevante devido a sua intensidade, pois ambos são completamente interconectados, ou seja, sem uma relação recíproca não há confiança, e consequentemente não haverá bons resultados na parceria. 
Para Nathan (2003) apud (JÚNIOR; LUNA; SOUSA, 2012), um bom relacionamento entre as partes é crucial, para tanto, destaca seis fatores imprescindível para o bom relacionamento, sendo eles: a definição clara dos papéis e responsabilidades; a possibilidade de diferentes percepções entre as partes; a alteração do estado emocional ou empolgação; a falta de diálogo; a satisfação e a rentabilidade baixa.

Com subsídio nas respostas dos entrevistados e suporte teórico, constata-se a existência de um relacionamento proativo entre franqueados e franqueador, de modo a contribuir para o fortalecimento do relacionamento, de forma transparente, aumentando os resultados e reduzindo pontos de possíveis conflitos.

\section{Considerações Finais}

Este estudo propôs analisar o perfil ideal de franqueado para a rede de drogarias DrogaShop, bem como as motivações dos franqueados para a inserção no sistema de franquias e a percepção do relacionamento com o franqueador.

Com relação ao objetivo de investigar o perfil ideal de franqueado na concepção do franqueador, verificou-se que não existe um perfil ideal para atuar no sistema de franquias da rede de drogarias DrogaShop, mas é observado entre os candidatos a capacidade de planejamento, expectativas em relação ao tempo de retorno do investimento, bem como, a disposição do futuro franqueado para manter-se totalmente presente, principalmente no início do negócio, ou seja "rala" e não apenas investir o dinheiro e pronto.

Ao investigar entre os franqueados suas motivações para empreenderem no sistema de franquias da DrogaShop, constatou que buscavam formas mais seguras para investir, pois compreendiam as barreiras de entrada no mercado, bem como as dificuldades de atuar sem suporte em um ambiente altamente competitivo. Os franqueados relataram que o sistema aumenta a vantagem competitiva, seja pela forma como os produtos são adquiridos, gerando economia de escala, compreendem ainda a importância e o retorno que a marca oferece, além do suporte para a condução do negócio.

Por fim, a percepção do relacionamento dos franqueados com o franqueador, buscou compreender a forma como avaliavam a interação entre demandas apresentadas e as contrapartidas obtidas. Diante do exposto, é possível inferir que há um relacionamento positivo e proativo entre as partes, considerando que o franqueador tem um atendimento solicito com atenção às demandas, apresentação de novidades do mercado, auxílio nas ações de divulgação dos produtos, além do suporte, seja pela visita do supervisor ou de forma remonta, estando sempre atentos às solicitações dos franqueados.

Apesar do estudo ter alcançado seus objetivos e ter respondido a problematização, a pesquisa continua aberta para novas abordagens, seja no segmento da franquia em estudo, quanto em outras áreas do mercado.

Como sugestões para estudos futuros, sugere-se ampliar as investigações em outras lojas da rede de drogarias DrogaShop, a fim de mapear estrategicamente o perfil dos fraqueados, considerando suas motivações para inserção no sistema de franquias, bem como a percepção que detém do relacionamento com o franqueador. Desta forma, almeja continuadamente consolidar o sistema de franchising, fortalecendo a marca, buscando meios para implementação de melhorias e consequentemente à maximização dos resultados tanto para o franqueador quanto para o franqueado. 


\section{Referências}

ANJOS, A. M. S. dos. Análise do sistema de franchising da EVA BAG \& SHOES: percepções da relação entre o franqueador e os franqueados. Relatório de Estágio Supervisionado (Administração), Universidade Federal de Campina Grande, 2015.

ASSOCIAÇÃO BRASILEIRA DE FRANCHISING (ABF). Desempenho em Franchising em 2018. Disponível em: < https://www.abf.com.br/numeros-do-franchising/>. Acessado em: 27 de maio 2019.

AZEVEDO, P.; SILVA, A. Entre a autoridade e a autonomia: as gerações de franchising. Proceedings of the International Conference on Economics and Agri-Food Networks Management, New York, NY, USA, 4. 2003.

BRASIL. Lei $\mathbf{n}^{\mathbf{0}} \mathbf{8 . 9 5 5}$, de 15 de dezembro de 1994. Dispõe sobre o contrato de franquia empresarial (franchising) e dá outras providências. Disponível em: <http://www.planalto.gov.br/ccivil_03/leis/18955.htm>. Acesso em: 02 jun. 2019.

COMBS, J. G.; KETCHEN JR, D. J. Why do firms use franchising as an entrepreneurial strategy? a meta-analysis. Journal of Management. v. 29 n. 3 p. 443-465, 2003.

CORREA, P. S. A.; HOLTEGEBAUM, M.; MACHADO, H. V. Análise do perfil empreendedor dos franqueados de escolas de idiomas na cidade de Londrina, Paraná. Anais do XXIV Simpósio de Gestão da Inovação Tecnológica, Rio Grande do Sul, 2006. Disponível em: 〈http://www.anpad.org.br/admin/pdf/ENN70.pdf>. Acesso em: 15 ago. 2019.

DEGOBBI, A. F. A percepção do franqueado às interações formais e informais com o franqueador: um estudo exploratório na região de Osasco. Dissertação (Mestrado em Administração), Faculdade de Campo Limpo Paulista - FACCAMP, São Paulo, 2013.

DROGASHOP. Descrição da empresa - missão, visão, valores. Disponível em: <http://www.drogashop.com/empresa/sobre-nos/>. Acesso em: 18 jun. 2019.

FARIAS FILHO, M. C.; ARRUDA FILHO, E. J. M. Planejamento da Pesquisa Científica. 1. ed. São Paulo: Atlas, 2013.

GIGLIOTTI, B. S. Transferência de conhecimento nas franquias brasileiras. Dissertação (Mestrado em Administração), Escola de Administração de Empresas de São Paulo, 2010.

HITT, M. A.; IRELAND, R. D.; HOSKISSON, R. E. Administração Estratégica: Competitividade e Globalização. São Paulo: Pioneira Thomson Learning, 2001.

ISAAC, V. R.; MELO, P. L. R.; BORINI, F. M. Redes de Franquias Estrangeiras e Domésticas em um Mercado Emergente: Análise Comparativa. RAC - Revista de Administração Contemporânea, Rio de Janeiro, v. 22, n. 1, art. 3, pp. 46-69, jan./fev., 2018. 
KICH, M. C. Avaliação de desempenho de uma rede de franquias do segmento cerâmico, fundamentado na metodologia multicritério de apoio à decisão construtivista (MCDA-C). Dissertação (Mestrado em Administração), Universidade do Sul de Santa Catarina, 2013.

LAKATOS, E. M. Fundamentos de metodologia científica. São Paulo: Atlas 2003.

LIMA JR., A. S. de; LUNA, R. M.; SOUSA, A. R. de. REMark - Revista Brasileira de Marketing, São Paulo, v. 11, n. 1, p. 94-112, jan./abril. 2012.

LUIZ, D. L.; MOTOKI, L. Y.; VILELA, J. A. A.; Ura, I. H. N.; LOURENZANI, A. E. B. S. Franchising como forma de negócio: um estudo preliminar no município de Tupã (SP). Anais do XXX da ANPAD, Bahia, 2006. Disponível em: < http://www.anpad.org.br/admin/pdf/enanpad2006-gctc-2204.pdf>. Acesso em: 15 jun. 2019.

MASCARENHA M. P.; HYGINO M. O.; SILVA N. L. Empreendendo em franchising: uma análise das principais vantagens e desvantagens. Revista de Empreendedorismo, Gestão e Negócios - FATECE, São Paulo, v. 4, n. 4, mar. p. 111-133, 2015. Disponível em: $<$ http://www.fatece.edu.br/arquivos/arquivos\%20revistas/empreendedorismo/volume4/6.p df $>$. Acesso em: 10 jul. 2019.

MAURO, P. C. Guia do Franqueador: Leitura obrigatória para quem quer comprar uma franquia. São Paulo: NOBEL, 2007.

Guia do Franqueador: Como fazer sua empresa crescer com o franchising. 4. ed. São Paulo: NOBEL, 2006.

MELO, P. L. de R.; BORINI, MENDES, F.; CUNHA, J. A. C. da. Percepções de valor e elementos estruturantes das microfranquias. RAC - Revista de Administração Contemporânea, Rio de Janeiro, v. 18, n. 3, art. 5, pp. 328-350, maio/jun. 2014.

PARENTE, J. Varejo no Brasil: gestão e estratégia. São Paulo: Atlas, 2000.

RODRIGUES, C. R. Desafios do modelo de franquias no setor de perfumaria e cosméticos brasileiro, sob o ponto de vista de franqueados e franqueadores. Dissertação (Mestrado em Administração), Fundação Getúlio Vargas - FGV, São Paulo, 2010.

SERVIÇO BRASILEIRO DE APOIO ÀS MICRO E PEQUENAS EMPRESAS (SEBRAE). Conhecendo como funciona o sistema e encontrando uma franquia adequada. 2018. Disponível em: <http://www.sebrae.com.br/Sebrae/Portal\%20Sebrae/Anexos/franquias_portal_sebrae.pdf>. Acesso em: 20 maio 2019.

SILVA, A. N. A percepção dos franqueados com relação as vantagens e desvantagens de se obter uma franquia: um estudo de caso no setor alimentício de um shopping de Campina Grande. Trabalho de conclusão de curso (Graduação em Ciências Contábeis). Universidade Estadual da Paraíba, Paraíba, 2014. Disponível em: < 
https://docplayer.com.br/amp/9878431-Universidade-estadual-da-paraiba-campus-i-campinagrande-centro-de-ciencias-sociais-aplicadas-curso-de-graduacao-em-cienciascontabeis.html>. Acesso em: 05 jun. 2019.

SILVA, E. L. da.; MENEZES, E. M. Metodologia da pesquisa e elaboração de dissertação. 4. ed. Florianópolis: UFSC, 2005. Disponível em: < https://projetos.inf.ufsc.br/arquivos/Metodologia_de_pesquisa_e_elaboracao_de_teses_e_diss ertacoes_4ed.pdf >. Acesso em 20 maio 2019.

SOUZA, G. C. de; LOURENZANI, A. E. B. S. A importância do perfil do franqueado para o sucesso das franquias: uma análise da capacidade empreendedora. Anais do XXX ENEGEP, São Paulo, 2010. Disponível em: http://www.abepro.org.br/biblioteca/enegep2010_tn_sto_119_775_16576.pdf>. Acesso em 15 jun. 2019. 